\title{
Haemosporidian Blood Parasites in nestling birds of prey in Mongolia
}

\author{
Hamidreza Attaran ${ }^{1,2 *}$, Jing Luo ${ }^{1}$, Wang Bo ${ }^{1}$, Reza Nabavi ${ }^{3}$, Hong-xuan He ${ }^{1}$ \\ 1- National Research Center for Wildlife Born Diseases, Institute of Zoology, Chinese Academy of Sciences, \\ Beijing, China \\ 2- Cell and Molecular Biology and Microbiology Department, Biological Science and Technology College, \\ University of Isfahan, Isfahan, Iran \\ 3- Parasitology Department, Pathobiology, Faculty of Veterinary Medicine, University of Zabol, Zabol, Iran
}

\begin{abstract}
*Corresponding author:
Hamidreza Attaran: Cell and Molecular Biology and Microbiology Department, Biological Science and Technology College, University of Isfahan, Isfahan, Iran

National Research Center for Wildlife-borne Diseases Institute of Zoology, Chinese Academy of Sciences, Beijing, China

Email: h.attaran@bio.ui.ac.ir

Phone: +98-9121437121
\end{abstract}

\begin{abstract}
Haemosporidians are vector-transmitted intracellular parasites that happen in numerous bird species worldwide and may possibly have important effects for wild bird populations. Studies of haemosporidians most dedicated on Europe and North America, and only newly some study in the Neotropics has been done, where the occurrence and influences of the disease have been less considered and are not understood well. In this study we designed a study in the nestling birds of prey in Mongolia. We sampled blood from 72 raptors at 2 different species and evaluated avian haemosporidian infection by two nested PCR protocol and one Real time PCR protocol. Sequencing a portion of the cytochrome b (cyt b) gene of the parasite. From the sampled birds, $10 \%$ were infected by Plasmodium. Inclusive, our findings advocate a high haemosporidian species richness in the bird community of Mongolia. In view of the frequency of local habitat loss that in this area is living, recognize how avian haemosporidians affect bird populations it is very important; in addition, more exhaustive sampling is required to fully understand the range of avian haemosporidian infection in this area.
\end{abstract}

Keywords: Haemosporidian Blood parasites, Birds of prey, Mongolia

\section{Introduction}

Understanding the threats of wild animal infectious disease for wildlife conservation is a principal issue $[1,2]$. This issue is becoming more important as climate change-induced territory 
changes are rapidly affecting the spreading of parasites and hosts [3]. In the last few decades we had observed an increase in the incidence of some infectious diseases in wild populations [4-6] and these be able to have a significant impression on wildlife populations[1].

Avian haemosporidian parasites (phylum Apicomplexa, order Heamosporida) are belonging to families Heamoproteidae, Plasmodiidae and Leucocytozidae. They are vector-borne parasites and infect most bird families [7]. Heamosporidian parasites are transmited by 17 genera of blood-sucking insects like, biting midges, louse flies, black flies and mosquitoes [7, 8]. The study of these parasites helps us as model of the host-parasite interactions in ecology, evolution and conservation biology. Avian haemosporidian parasites are cosmopolitan in distribution and indirectly reduce host fitness by decreasing their reproductive success and increasing breeding energy cost [9].Therefore, haemosporidian parasites constitutes a selective force on bird population. Accordingly, interactions of haemosporidian parasites and birds have become a model of host-parasite relationship in ecology, conservation and vertebrate management $[8,10]$. Among haemosporidian parasites, Plasmodium has been linked to the mortality and populationlevel declines in native birds in some region [11]. Despite of their broad host and geographic distribution, information on haemosporidian pathogenicity is almost based on laboratory experiments with domestic birds [7].

Raptor birds (Accipitriformes and Strigiformes) are located at the top of the food chain. Despite they play important roles in the ecosystem but most studies of avian haemosporidian have been conducted on passerines (Passeriforms), with very little focus on raptor hosts [12, 13].More studies are critical to progress our knowledge of the genetic variability, true diversity and host specificity of blood parasites in raptor birds $[14,15]$.

Studies on raptors in comparison with passerines are infrequent and have been mostly performed on captive, injured or migratory birds [13, 16-19]. However has been unpaid to the breeding populations of sedentary raptor species, although studies on nestling have several advantages: they are immunologically naive and highly susceptible to infection, detected parasites supposedly originates from the study site, and the acute phase of infection has no effect on sampling since they are immobile [20-25].

Furthermore, while the blood parasites are generally thought to be harmless, we have evidence that infection can be harmful [26]. Studies have suggested that avian haemosporidian infection can cause reduced strength in flight; reduce speed, poor appetite, anemia, weight loss, airsacculitis, arthritis, lower reproductive success, reduced lifespan and death [6, 26-29].

However the environment modulates infection risk. Avian haemosporidian infection has been linked with environmental variables such as altitude, temperature, and precipitation [30].

On the other hand, studies of haemosporidians most dedicated on Europe and North America, and only newly some studies in the Neotropics has been done [31-34]. 
Presented haemosporidians in isolated areas may pose a threat to naïve endemic birds that have not evolved ways to counteract the infection. For instance, haemosporidian vectors were accidentally introduced to the islands after some Hawaiian birds that suffered large population declines $[35,36]$

Mongolia is located in north of China and we don't have any information about rate of haemosporidian parasites in birds and specially birds of prey there. Because of low human population and huge grass land any information from diseases will be very important specially for china because they are close and any infection can easily come to china from Mongolia.

In the last two decades, molecular biological tools have been obtained to study haemosporidian parasites of bird [37-39] DNA-based techniques make detection of haemosporidians easier, particularly during chronic infections and at early stages of infections, when parasitaemia is low and parasites can be over- looked in blood smears [40]. The progress in this field is directly joined to the development of a standard nested PCR protocol for amplifying a segment of the haemosporidian cytochrome b gene $[38,41,42]$

The goal of this survey was to conduct an initial study of the incidence of avian haemosporidian parasites in the endemic bird area of the Mongolia, home to a variety of biomes and one of the world's important avian centers of endemism. In addition to habitat-related threats, the local avifauna could also be exposed to infectious diseases, which could exacerbate the effects of habitat reduction on the local populations.

\section{Material and Methods:}

\section{Study area and Sampling}

Seventy-two nestling of raptors (70 Saker falcons, and 2 common buzzards) between two till five weeks old were sampled in Mongolia (Bayan district near Ulaan Baatar) during June 2016.

Blood samples after separating serum stored at -80

DNA extraction, PCR amplification, sequencing and parasite detection

Total DNA was extracted from RBC cells using DNA extraction tissue Kit. The existence and quality of DNA was inspected by the spectrophotometer NanoDrop ND-1000.

Samples were screened for blood parasites of the genera Haemoproteus, Plasmodium and Leucocytozoon with two nested PCR protocols and one Real Time PCR Protocol. 


\section{The first nested PCR protocol}

For the first way, two modified nested PCR were used to amplify fragments of the cyt b gene (Table 2). The protocol for Haemoproteus/Plasmodium was based on the standard protocol of Waldenström et al. [42]. But with newly designed forward primers, H332F and H350F [43](Fig. 1, Table 2), which match more closely with available GenBank sequences. The protocol produces a $477 \mathrm{bp}$ fragment, which is only one base pair shorter than the fragment produced by the Waldenström et al. protocol [42]. The Leucocytozoon protocol uses the initial primer sets described by Hellgren et al.[41] but with newly designed nested primers (Fig. 1, Table 2). This new protocol produces a $526 \mathrm{bp}$ fragment that encompasses the $478 \mathrm{bp}$ fragment produced by the Hellgren protocol [43].

The second protocol involved a first pre amplification PCR step with the primers Plas1F [44] and HaemNR3 [41], followed by a nested PCR step with the internal primers 3760F [37] and the HaemJR4 [14]. This protocol uses the same PCR conditions as in Waldenström et al. (2004)[42], but it amplifies a 542 bp fragment of the parasite's cytochrome b that includes the fragment amplified by the primers of Waldenström et al. (2004), and amplifies DNA from all three parasite genera in a single nested PCR.

PCR products were checked in $2 \%$ agarose gels stained with GelRed ${ }^{\mathrm{TM}}$ (Biotium, USA) under UV light, looking for bands of the appropriate size. A positive control (using DNA template from an infected bird) and eight negative controls (using distilled water instead of template DNA) were included in every 96-well PCR batch to test for reaction performance and to control for PCR contamination (no negative control yielded a positive result).

Also one real time PCR protocol

\begin{tabular}{|c|c|}
\hline Protocol/primer & Primer sequence \\
\hline $\begin{array}{l}\text { Nested PCR - Haemoproteus and Plasmodium } \\
\text { H332Fa } \\
\text { HAEMNR2b } \\
\text { H350Fa } \\
\text { HAEMR2c }\end{array}$ & $\begin{array}{l}\text { 5' - GAGAATTATGGAGYGGATGGTG - } \text { 3' }^{\prime} \\
5^{\prime} \text { - AGAGGTGTAGCATATCTATCTAC- } 3^{\prime} \\
5^{\prime} \text { - GGTGTTTTAGATATATGCATGC - 3' } \\
\text { 5 }^{\prime} \text { - GCATTATCTGGATGTGATAATGGT - } 3\end{array}$ \\
\hline $\begin{array}{l}\text { Nested PCR - Leucocytozoon } \\
\text { HAEMNFId } \\
\text { HAEMNR3d } \\
\text { L350Fe } \\
\text { L890R }\end{array}$ & $\begin{array}{l}5^{\prime} \text { - CATATATTAAGAGAAITATGGAG - } 3^{\prime} \\
5^{\prime} \text { - ATAGAAAGATAAGAAATACCATTC - } 3^{\prime} \\
5^{\prime} \text { - GGTGTTTTAGATACTTA - } 3^{\prime} \\
5^{\prime} \text { - TACAATATGTTGAGGTGTTTG - } 3^{\prime}\end{array}$ \\
\hline $\begin{array}{l}\text { Plas1F } \\
\text { HaemNR3 } \\
3760 F \\
\text { HaemJR4 }\end{array}$ & $\begin{array}{l}\text { GAGA- ATTATGGAGTGGATGGTG } \\
\text { ATAGAAAGATAAGAAATACCATTC } \\
\text { GAGTGGATGGTGTTTAGAT } \\
\text { GAAATACCATTCTGGAACAATATG }\end{array}$ \\
\hline
\end{tabular}




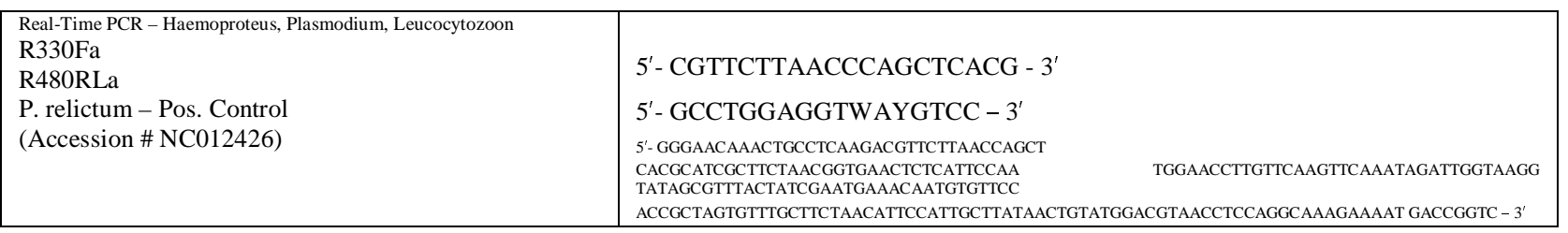

\section{Phylogenetic analysis}

The phylogenetic tree was build using Maximum Likelihood (ML) analysis based on the Kimura 2-parameter model (Kimura 1980) in the program MEGA 7 (Tamura et al. 2013).

\section{Results}

Sequencing of the 7 PCR products that were positive for haemosporidian infection revealed a total of 2 unique sequences that grouped into lineages (Table 2, Figure 2). All sequences identified had a sequence identity of at least $99 \%$ to sequences reported in GenBank (Table 2), 2 of these had not been previously reported and have been deposited in GenBank. Four lineages had $100 \%$ match to sequences previously reported. One lineage had $100 \%$ match to Plasmodium sp., a lineage that has previously been reported in China (Table 2). The phylogenetic analysis of the identified sequences revealed 2 lineages of Plasmodium (Fig. 1). The tree had wellsupported nodes, except for the node separating (Fig. 2).

\begin{tabular}{|l|l|l|l|}
\hline Sample & Nested PCR (protocol 1) & Nested PCR (protocol 2) & Real-time PCR \\
\hline 2 & & positive & \\
\hline 6 & positive & & Positive \\
\hline 18 & positive & & \\
\hline 22 & & positive & \\
\hline 27 & & positive & \\
\hline 34 & & positive & \\
\hline 46 & & positive & \\
\hline
\end{tabular}




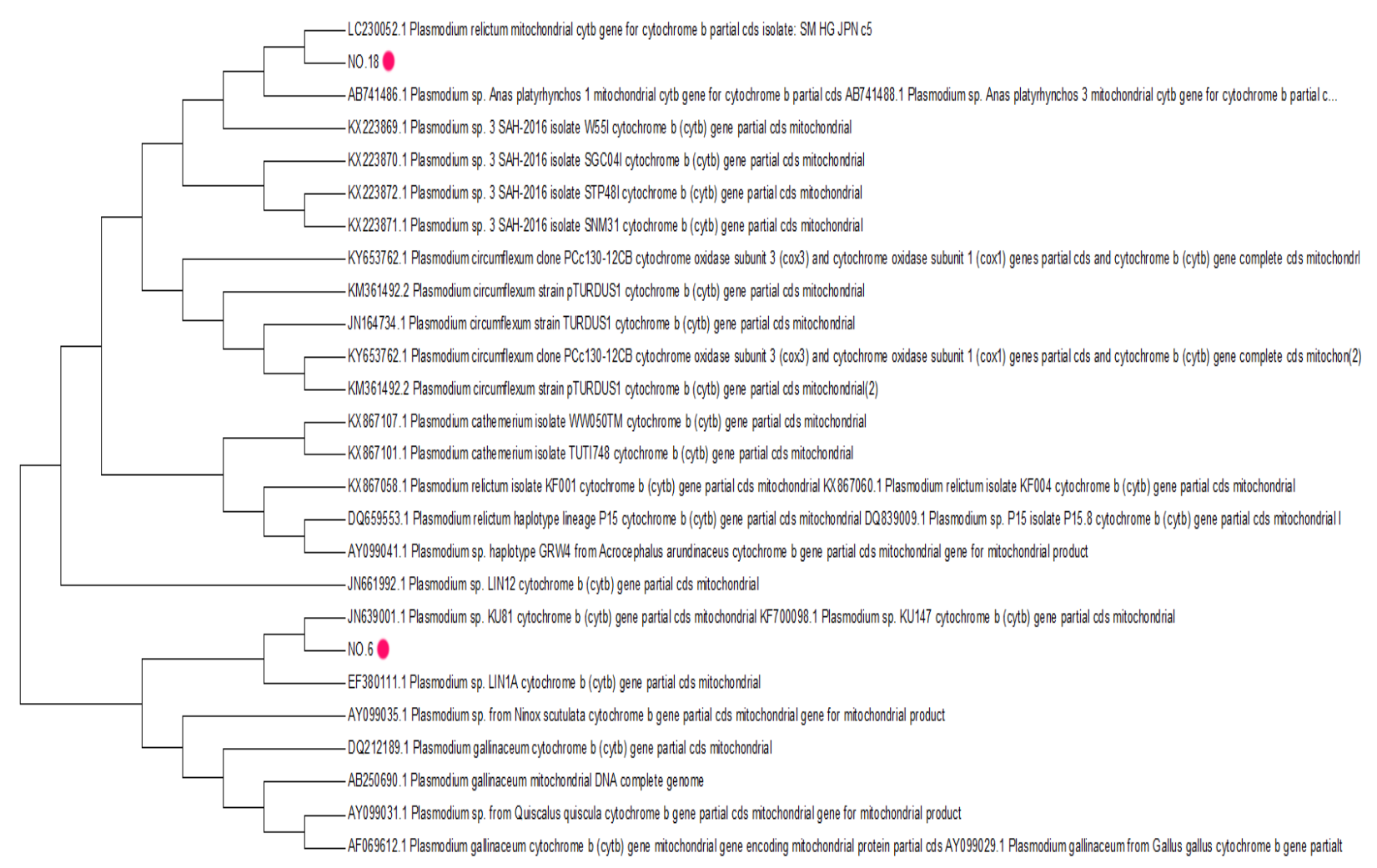

\section{Discussion}

In this study we evaluated infection by haemosporidians in nestling birds of prey from the Mongolia, an important area, and report a possible new blood parasite-host association. Our results obviously showed that the real number of haemosporidian lineages in this area is possible to be much higher than the numbers we found. Considering the protection concerns and its endemic species, the ecology of these parasite - host associations needs to be further discovered.

We found an overall incidence of haemosporidians of $10 \%$. This result concurs with prevalence reported for the González et al. 2015, Krone et al. 2008 and Remple 2004, lierz 2008 [13, 26, 33]. In contrast, a previous large-scale study [22, 45, 46].

In the present study we assessed the molecular identity of avian haemosporidians infecting Raptors, as well as the differences in parasite diversity by three protocols. Although prevalence was generally low. 
The purpose of any new screening method is to afford an accurate estimate of parasite prevalence and to offer advantages over already established methods. Although in some previous studies reputed, the real-time PCR protocol as effective as the two most widely used molecular screening methods for haemosporidian parasites in birds [42, 47], in another study reported that all three methods likely leave a small proportion of samples undetected [43]

Recent studies have shown in regions with high avian diversity and in specific host populations [48], the Leucocytozoon diversity would be high[49] accessibility of a screening method that can amplify all three genera can serve up in understanding the accurate diversity and ecology of all three genera of avian haemosporidian parasites. Since now, the only screening process that could distinguish all three genera in a single method were microscopy and the restriction digestion protocol of Beadell \& Fleischer [50], but both take drastically more time than the real-time PCR and nested PCR protocols. Although Plasmodium spp. was only found in Mongolia, further studies are needed through a larger elevation gradient to further support our findings. We did not measure other environmental variables that could potentially affect the prevalence of haemosporidians in this area.

Our data revealed incidence of avian Plasmodium in Mongolia from birds of prey. Given Mongolia is considered a center of endemism, high prevalence and diversity of haemosporidians suggests a threat for wildlife.

Once a comprehensive screening of haemosporidians in the wild avifauna is performed, further studies should focus on determining the factors that modulate infection and transmission in the area and assessing the effects of haemosporidian infection on various aspects of host fitness.

\section{Refrences:}

1. Scott ME. The impact of infection and disease on animal populations: implications for conservation biology. Conservation Biology. 1988;2(1):40-56. doi: 10.1111/j.1523-1739.1988.tb00334.x. PubMed PMID: ZOOREC:ZOOR12500026076.

2. Thompson RC, Lymbery Aj Fau - Smith A, Smith A. Parasites, emerging disease and wildlife conservation. (1879-0135 (Electronic)).

3. Garamszegi LZ. Climate change increases the risk of malaria in birds. Glob Change Biol. 2011;17(5):1751-9. doi: 10.1111/j.1365-2486.2010.02346.x. PubMed PMID: WOS:000289117100001.

4. Daszak $P$, Cunningham AA, Hyatt AD. Emerging infectious diseases of wildlife--threats to biodiversity and human health. Science (New York, NY). 2000;287(5452):443-9. Epub 2000/01/22. PubMed PMID: 10642539.

5. Dobson A, Foufopoulos J. Emerging infectious pathogens of wildlife. Philosophical transactions of the Royal Society of London Series B, Biological sciences. 2001;356(1411):1001-12. Epub 2001/08/23. doi: 10.1098/rstb.2001.0900. PubMed PMID: 11516378; PubMed Central PMCID: PMCPMC1088495. 6. Gonzalez-Quevedo C, Pabon A, Fabio Rivera-Gutierrez H. Prevalence of haemosporidians in a Neotropical endemic bird area. Avian Conservation and Ecology. 2016;11(1). doi: 10.5751/ace-00834110107. PubMed PMID: WOS:000379869400007. 
7. Valkiunas G, Valkiunas G. Avian malaria parasites and other haemosporidia: CRC Press; 2005. i-x, 1-932 p.

8. Braga EM, Silveira P, Belo NO, Valkiunas G. Recent advances in the study of avian malaria: an overview with an emphasis on the distribution of Plasmodium spp in Brazil. Memorias Do Instituto Oswaldo Cruz. 2011;106:3-11. doi: 10.1590/s0074-02762011000900002. PubMed PMID: WOS:000294440600002.

9. Belo NO, Rodriguez-Ferraro A, Braga EM, Ricklefs RE. Diversity of avian haemosporidians in arid zones of northern Venezuela. Parasitology. 2012;139(8):1021-8. doi: 10.1017/s003118201200039x. PubMed PMID: WOS:000306869800006.

10. Deviche P, McGraw K, Greiner EC. Interspecific differences in hematozoan infection in sonoran desert Aimophila sparrows. Journal of Wildlife Diseases. 2005;41(3):532-41. doi: 10.7589/0090-355841.3.532. PubMed PMID: WOS:000233016900008.

11. Niebuhr CN, Blasco-Costa I. Improving detection of avian malaria from host blood: a step towards a standardised protocol for diagnostics. Parasitology Research. 2016;115(10):3905-11. doi: 10.1007/s00436-016-5157-4.

12. Clark NJ, Clegg SM, Lima MR. A review of global diversity in avian haemosporidians (Plasmodium and Haemoproteus: Haemosporida): new insights from molecular data. International Journal for Parasitology. 2014;44(5):329-38. doi: 10.1016/j.ijpara.2014.01.004. PubMed PMID: WOS:000334898300009.

13. Krone O, Waldenstroem J, Valkiunas G, Lessow O, Mueller K, lezhova TA, et al. Haemosporidian blood parasites in European birds of prey and owls. Journal of Parasitology. 2008;94(3):709-15. doi: 10.1645/ge-1357.1. PubMed PMID: WOS:000257411200022.

14. Perez-Rodriguez A, de la Puente J, Onrubia A, Perez-Tris J. Molecular characterization of haemosporidian parasites from kites of the genus Milyus (Ayes: Accipitridae). International Journal for Parasitology. 2013;43(5):381-7. doi: 10.1016/j.ijpara.2012.12.007. PubMed PMID: WOS:000317557900006.

15. Sehgal RNM, Hull AC, Anderson NL, Valkiunas G, Markovets MJ, Kawamura S, et al. Evidence for crypticspeciation of Leucocytozoon spp. (Haemosporida, Leucocytozoidae) in diurnal raptors. Journal of Parasitology. 2006;92(2):375-9. doi: 10.1645/ge-656r.1. PubMed PMID: WOS:000237329400024.

16. Gutierrez-Lopez R, Gangoso L, Martinez-de la Puente J, Fric J, Lopez-Lopez P, Mailleux M, et al. Low prevalence of blood parasites in a long-distance migratory raptor: the importance of host habitat. Parasites \& Vectors. 2015;8. doi: 10.1186/s13071-015-0802-9. PubMed PMID: WOS:000351996300001. 17. Krone O, Priemer J, Streich J, Sommer P, Langgemach T, Lessow O. Haemosporida of birds of prey and owls from Germany. Acta Protozoologica. 2001;40(4):281-9. PubMed PMID: WOS:000172091900005.

18. Outlaw DC, Ricklefs RE. ON THE PHYLOGENETIC RELATIONSHIPS OF HAEMOSPORIDIAN PARASITES FROM RAPTORIAL BIRDS (FALCONIFORMES AND STRIGIFORMES). Journal of Parasitology. 2009;95(5):1171-6. doi: 10.1645/ge-1982.1. PubMed PMID: WOS:000272015500021.

19. Valkiunas G, Sehgal RNM, lezhova TA, Hull AC. IDENTIFICATION OF LEUCOCYTOZOON TODDI GROUP (HAEMOSPORIDA: LEUCOCYTOZOIDAE), WITH REMARKS ON THE SPECIES TAXONOMY OF LEUCOCYTOZOIDS. Journal of Parasitology. 2010;96(1):170-7. doi: 10.1645/ge-2109.1. PubMed PMID: WOS:000276417400024.

20. Ashford RW, Green EE, Holmes PR, Lucas AJ. LEUCOCYTOZOON-TODDI IN BRITISH SPARROWHAWKS ACCIPITER-NISUS - PATTERNS OF INFECTION IN NESTLINGS. Journal of Natural History. 1991;25(2):269-77. doi: 10.1080/00222939100770191. PubMed PMID: WOS:A1991FK14900001.

21. Ashford RW, Wyllie I, Newton I. LEUCOCYTOZOON-TODDI IN BRITISH SPARROWHAWKS ACCIPITER-NISUS - OBSERVATIONS ON THE DYNAMICS OF INFECTION. Journal of Natural History. 1990;24(5):1101-7. doi: 10.1080/00222939000770691. PubMed PMID: WOS:A1990DZ31500003. 
22. Hanel J, Dolezalova J, Stehlikova S, Modry D, Chudoba J, Synek P, et al. Blood parasites in northern goshawk (Accipiter gentilis) with an emphasis to Leucocytozoon toddi. Parasitology Research. 2016;115(1):263-70. doi: 10.1007/s00436-015-4743-1. PubMed PMID: WOS:000370868600027.

23. Jasper MA, Hull JM, Hull AC, Sehgal RNM. Widespread lineage diversity of leucocytozoon blood parasites in distinct populations of western Red-tailed Hawks. Journal of Ornithology. 2014;155(3):76775. doi: 10.1007/s10336-014-1064-6. PubMed PMID: WOS:000337792500021.

24. Lei B, Amar A, Koeslag A, Gous TA, Tate GJ. Differential Haemoparasite Intensity between Black Sparrowhawk (Accipiter melanoleucus) Morphs Suggests an Adaptive Function for Polymorphism. Plos One. 2013;8(12). doi: 10.1371/journal.pone.0081607. PubMed PMID: WOS:000329325200004.

25. Svobodova M, Weidinger K, Peske L, Volf P, Votypka J, Vorisek P. Trypanosomes and haemosporidia in the buzzard (Buteo buteo) and sparrowhawk (Accipiter nisus): factors affecting the prevalence of parasites. Parasitology Research. 2015;114(2):551-60. doi: 10.1007/s00436-014-4217-x. PubMed PMID: WOS:000348566000021.

26. Remple JD. Intracellular hematozoa of raptors: A review and update. Journal of Avian Medicine and Surgery. 2004;18(2):75-88. doi: 10.1647/2003-008. PubMed PMID: WOS:000222558200001.

27. Merino S, Moreno J, Sanz JJ, Arriero E. Are avian blood parasites pathogenic in the wild? A medication experiment in blue tits (Parus caeruleus). Proceedings of the Royal Society B-Biological Sciences. 2000;267(1461):2507-10. doi: 10.1098/rspb.2000.1312. PubMed PMID: WOS:000166426100006.

28. Remple JD. Avian malaria with comments on other Haemosporidia in large falcons. Cooper JE, Greenwood AG, editors1981. 107-10 p.

29. Dawson RD, Bortolotti GR. Effects of hematozoan parasites on condition and return rates of American Kestrels. Auk. 2000;117(2):373-80. doi: 10.1642/0004-8038(2000)117[0373:eohpoc]2.0.co;2. PubMed PMID: WOS:000086623700010.

30. Sehgal RN. Manifold habitat effects on the prevalence and diversity of avian blood parasites. International journal for parasitology Parasites and wildlife. 2015;4(3):421-30. Epub 2016/02/03. doi: 10.1016/j.ijppaw.2015.09.001. PubMed PMID: 26835250; PubMed Central PMCID: PMCPMC4699977. 31. Lacorte GA, Felix GM, Pinheiro RR, Chaves AV, Almeida-Neto G, Neves FS, et al. Exploring the diversity and distribution of neotropical avian malaria parasites--a molecular survey from Southeast Brazil. PloS one. 2013;8(3):e57770. Epub 2013/03/08. doi: 10.1371/journal.pone.0057770. PubMed PMID: 23469235; PubMed Central PMCID: PMCPMC3585926.

32. Clark NJ, Clegg SM, Lima MR. A review of global diversity in avian haemosporidians (Plasmodium and Haemoproteus: Haemosporida): new insights from molecular data. International journal for parasitology. 2014;44(5):329-38. Epub 2014/02/22. doi: 10.1016/j.ijpara.2014.01.004. PubMed PMID: 24556563.

33. Gonzalez AD, Lotta IA, Garcia LF, Moncada LI, Matta NE. Avian haemosporidians from Neotropical highlands: Evidence from morphological and molecular data. Parasitology international. 2015;64(4):48-59. Epub 2015/02/02. doi: 10.1016/j.parint.2015.01.007. PubMed PMID: 25638289.

34. Marzal A, Garcia-Longoria L, Cardenas Callirgos JM, Sehgal RNM. Invasive avian malaria as an emerging parasitic disease in native birds of Peru. Biological Invasions. 2015;17(1):39-45. doi: 10.1007/s10530-014-0718-x. PubMed PMID: WOS:000347526800006.

35. Warner RE. ROLE OF INTRODUCED DISEASES IN EXTINCTION OF ENDEMIC HAWAIIAN AVIFAUNA. Condor. 1968;70(2):101-\&. doi: 10.2307/1365954. PubMed PMID: WOS:A1968B238800001.

36. Vanriper C, Vanriper SG, Goff ML, Laird M. THE EPIZOOTIOLOGY AND ECOLOGICAL SIGNIFICANCE OF MALARIA IN HAWAIIAN LAND BIRDS. Ecological Monographs. 1986;56(4):327-44. doi: 10.2307/1942550. PubMed PMID: WOS:A1986E853900003.

37. Beadell JS, Gering E, Austin J, Dumbacher JP, Peirce MA, Pratt TK, et al. Prevalence and differential host-specificity of two avian blood parasite genera in the Australo-Papuan region. Molecular 
Ecology. 2004;13(12):3829-44. doi: 10.1111/j.1365-294X.2004.02363.x. PubMed PMID: WOS:000225150000018.

38. Bensch S, Stjernman M, Hasselquist D, Ostman O, Hansson B, Westerdahl H, et al. Host specificity in avian blood parasites: a study of Plasmodium and Haemoproteus mitochondrial DNA amplified from birds. Proceedings of the Royal Society B-Biological Sciences. 2000;267(1452):1583-9. doi: 10.1098/rspb.2000.1181. PubMed PMID: WOS:000088765700013.

39. Ricklefs RE, Fallon SM. Diversification and host switching in avian malaria parasites. Proceedings of the Royal Society B-Biological Sciences. 2002;269(1494):885-92. doi: 10.1098/rspb.2001.1940. PubMed PMID: WOS:000175540100003.

40. Jarvi SI, Farias MEM, Baker H, Freifeld HB, Baker PE, Van Gelder E, et al. Detection of avian malaria (Plasmodium spp.) in native land birds of American Samoa. Conservation Genetics. 2003;4(5):629-37. doi: 10.1023/a:1025626529806. PubMed PMID: WOS:000185261600008.

41. Hellgren $O$, Waldenstrom J, Bensch S. A new PCR assay for simultaneous studies of Leucocytozoon, Plasmodium, and Haemoproteus from avian blood. J Parasitol. 2004;90(4):797-802. Epub 2004/09/11. doi: 10.1645/ge-184r1. PubMed PMID: 15357072.

42. Waldenstrom J, Bensch S, Hasselquist D, Ostman O. A new nested polymerase chain reaction method very efficient in detecting Plasmodium and Haemoproteus infections from avian blood. J Parasitol. 2004;90(1):191-4. Epub 2004/03/26. doi: 10.1645/ge-3221rn. PubMed PMID: 15040694. 43. Bell JA, Weckstein JD, Fecchio A, Tkach VV. A new real-time PCR protocol for detection of avian haemosporidians. Parasit Vectors. 2015;8:383. Epub 2015/07/19. doi: 10.1186/s13071-015-0993-0. PubMed PMID: 26187629; PubMed Central PMCID: PMCPmc4506571.

44. Duval L, Robert V, Csorba G, Hassanin A, Randrianarivelojosia M, Walston J, et al. Multiple hostswitching of Haemosporidia parasites in bats. Malaria journal. 2007;6:157. Epub 2007/11/30. doi: 10.1186/1475-2875-6-157. PubMed PMID: 18045505; PubMed Central PMCID: PMCPMC2212651. 45. Ciloglu A, Yildirim A, Duzlu O, Onder Z, Dogan Z, Inci A. Investigation of avian haemosporidian parasites from raptor birds in Turkey, with molecular characterisation and microscopic confirmation. Folia parasitologica. 2016;63. Epub 2016/08/11. doi: 10.14411/fp.2016.023. PubMed PMID: 27507297. 46. Lierz M, Hafez HM, Krone O. Prevalence of hematozoa in falcons in the United Arab Emirates with respect to the origin of falcon hosts. Journal of avian medicine and surgery. 2008;22(3):208-12. Epub 2008/11/19. doi: 10.1647/2007-025.1. PubMed PMID: 19014093.

47. Fallon SM, Ricklefs RE, Swanson BL, Bermingham E. Detecting avian malaria: an improved polymerase chain reaction diagnostic. The Journal of parasitology. 2003;89(5):1044-7. Epub 2003/11/25. doi: 10.1645/ge-3157. PubMed PMID: 14627154.

48. Reeves AB, Smith MM, Meixell BW, Fleskes JP, Ramey AM. Genetic diversity and host specificity varies across three genera of blood parasites in ducks of the Pacific Americas Flyway. PLoS One. 2015;10(2):e0116661. Epub 2015/02/25. doi: 10.1371/journal.pone.0116661. PubMed PMID: 25710468; PubMed Central PMCID: PMCPmc4339737.

49. Lutz HL, Hochachka WM, Engel JI, Bell JA, Tkach VV, Bates JM, et al. Correction: Parasite Prevalence Corresponds to Host Life History in a Diverse Assemblage of Afrotropical Birds and Haemosporidian Parasites. PLoS One. 2015;10(5):e0128851. Epub 2015/05/20. doi: 10.1371/journal.pone.0128851. PubMed PMID: 25984782; PubMed Central PMCID: PMCPmc4436124. 50. Beadell JS, Fleischer RC. A restriction enzyme-based assay to distinguish between avian hemosporidians. The Journal of parasitology. 2005;91(3):683-5. Epub 2005/08/20. doi: 10.1645/ge3412rn. PubMed PMID: 16108566. 
0.000 JN164734.1 Plasmodium circumflexum strain TURDUS1 cytochrome b (cytb) gene partial cds mitochondrial(2)

$0.000 \quad 0.000$ KM361492.2 Plasmodium circumflexum strain pTURDUS1 cytochrome b (cytb) gene partial cds mitochondrial(2)

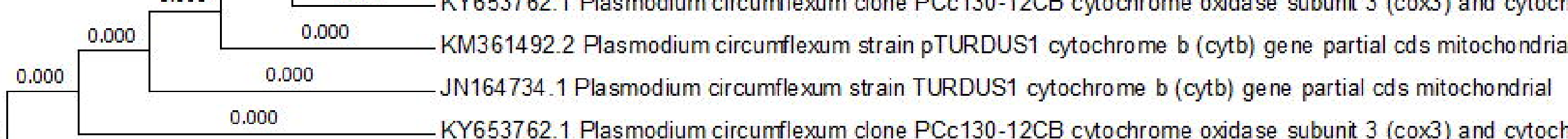

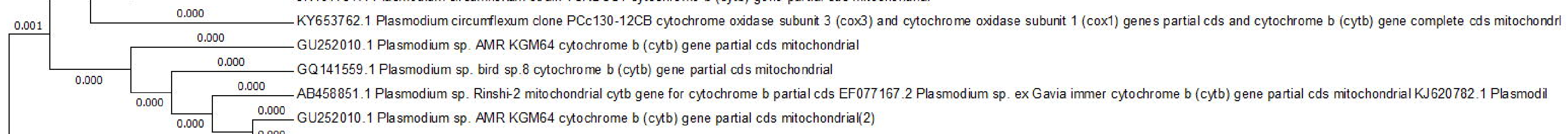

0.003

$0.000 \frac{0.000}{0.000}$ GQ141559.1 Plasmodium sp. bird sp.8 cytochrome b (cytb) gene partial cds mitochondrial(2)

$0.000 \quad 0.000$ AB741486.1 Plasmodium sp. Anas platyrhynchos 1 mitochondrial cytb gene for cytochrome b partial cds AB741488.1 Plasmodium sp. Anas platyrhynchos 3 mitochondrial cytb gene for cytochrome b partial c(2)

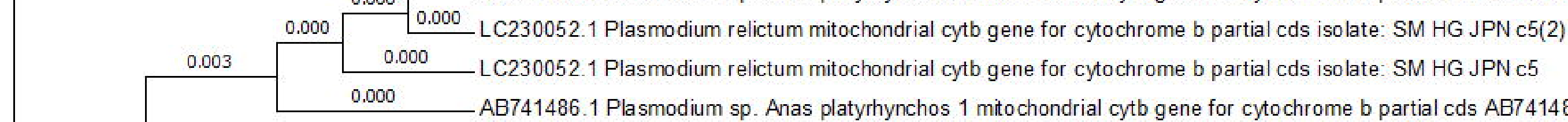

0.000

$\begin{array}{llll}0.000 & 0.003 & 0.000 & \text { AB308050.1 Plasmodium sp. mo squito132 mitochondrial cytb gene for apocytochrome b partial cds } \\ 0.000 & \text { AY733090.1 Plasmodium relictum isolate jb5.NAN015 mitochondrion complete genome }\end{array}$

0.003

0.002

0.002

0.001 AB542063.1 Plasmodium sp. mo squito U28 mitochondrial cytb gene for apocytochroncoding mitochondrial

0.000 KX867107.1 Plasmodium cathemerium isolate WW050TM cytochrome b (cytb) gene partial cds mitochondrial

0.000 AY099033.1 Plasmodium sp. from Turdus migratorius cytochrome b gene partial cds mitochondrial gene for mitochondrial product AY099033.1 Plasmodium sp. from Turdus migratorius cytochrome b gene partial cds mitochondrial gene for mitochondrial product(2) 0.004 NO.C-19 